Ilaha G. Jabrayilova

Institute of Information Technology of ANAS, Baku, Azerbaijan

DOI: $10.25045 /$ jpis.v08.i2.11

ilahe.jabrailova@gmail.com

\title{
SUPERIORITY AND PROBLEMS OF NEW MEDIA
}

The article explores the advantages of new media as an interactive communication and its role in shaping the public opinion. It analyzes the new media in comparison with the traditional one. Moreover, safety problems in the new media environment are reviewed.

Keywords: new media, traditional media, internet resources, interactive communication, information environment.

\section{Introduction}

The rapid development of information and communication technologies (ICT) has led to substantial changes and created new opportunities in the field of mass media and in all other spheres. The traditional forms of mass media such as radio, television and printed journalism have entered a new quality stage. New virtual media has emerged. ICT opportunities have historically caused serious problems in the media activity and removed space barriers. The Internet integrates all forms of media and enables it to operate on a single platform. The new media is also understood as the mass media that operates with the highest level of ICT opportunities.

The most important distinguishing feature of the new media is its interactivity. The Internet acts as a mediator, providing interactivity between information and its consumer. This feature of the new media revolutionizes the communication and interpersonal contact model in society. In addition, there are several advantages that make the new media more attractive than the traditional one. In general, websites, social networks, blogs and forums, mobile apps, podcasts, multimedia tools (audio-visual tools, animations, etc.) make the new media interesting and colorful. However, the new media is behind the traditional media, due to the principles of journalism, such as professionalism, responsibility, and credibility.

The article focuses on the advantages and disadvantages of the new media and comparatively analyzes the traditional media. The study involves the interactivity of the new media, its impact on the public opinion, the differences in the principles of online and offline media, and the existing security issues in the new information environment.

\section{New media as an interactive communication tool}

The informational environment and journalism has been fundamentally changed through the Internet, which is considered to be the foremost phenomenon of the XXI century. Expert in the field of media and journalism Prof. Russell Neuman states that the new media:

- $\quad$ Altered the meaning of geographic distance.

- Allowed for a huge increase in the volume of communication.

- Provided the possibility of increasing the speed of communication.

- Provided opportunities for interactive communication.

- Allowed forms of communication that were previously separate to overlap and interconnect [2].

The social networks, one of the most active tools of the new media, are now one of the most widespread communication tools in the society. According to the estimates, the ranking of social networking and messaging services for the first half of 2017 is as follows (Figure 1): 


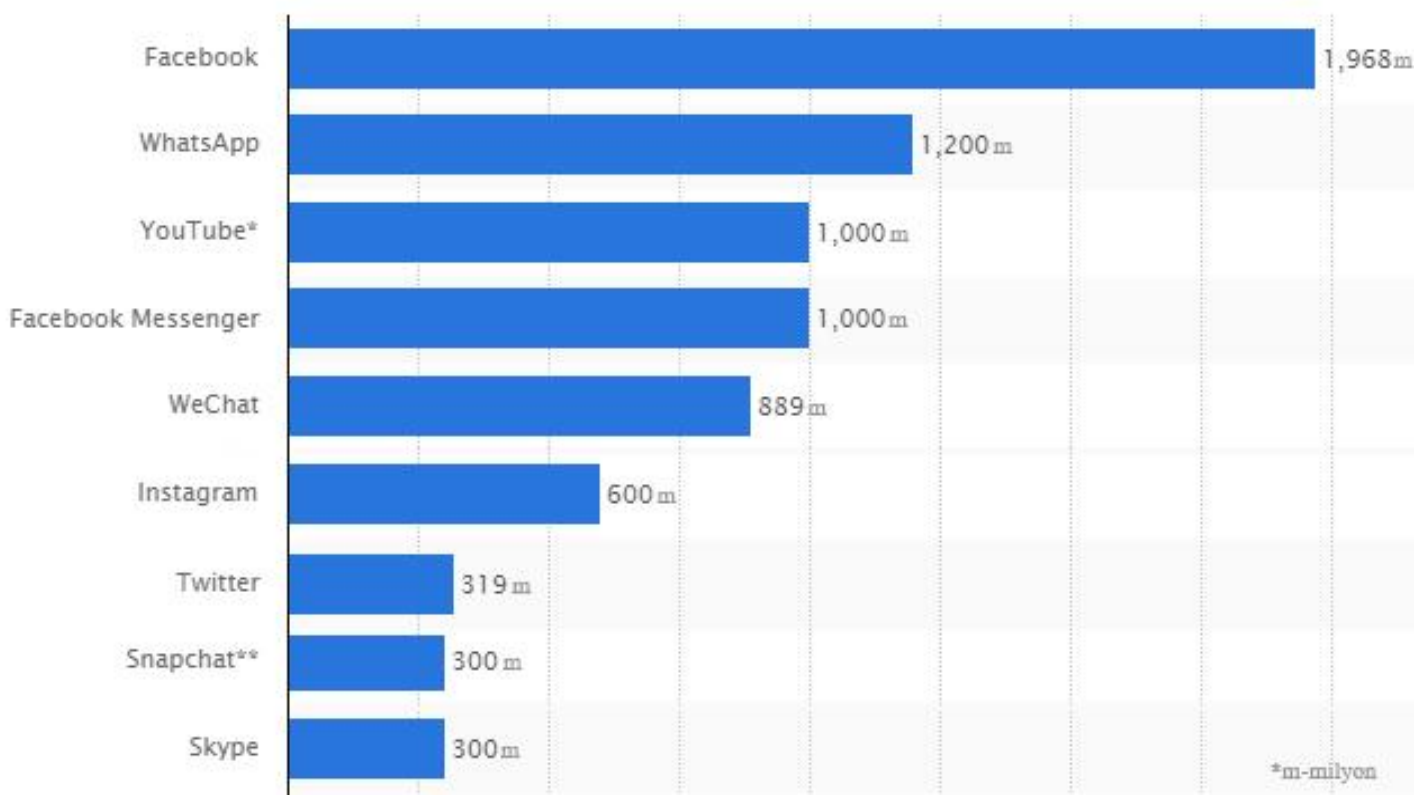

Figure 1. Statistics of use of social network and messaging services [3]

One of the key factors in the activities of the new media is the interactivity, although the separate media samples have different levels of interactivity. Tony Feldman writes in his book Introduction to Electronic Media that the number of digital satellite television broadcasting from new media technologies is increasing. However, the viewers are unable to interact to meet the needs of viewers. This means that, unlike digitalism, interactivity is not typical for all new media technologies [4]. In this sense, social networks and other communication means have considerable advantages.

The most commonly used messaging applications are the applications that can broadcast live. Live chat - Wechat, Facebook, WhatsApp, Messenger, Snapchat and many other similar applications are spreading faster than the social networks in recent years. For example, 49 percent of smartphone users aged from 18 to 29 benefits from messaging applications. 37 percent of relatively elder (from 30 to 49) smartphone users, and only 24 percent of the users aged 50 and older use these applications [5] .Thus, the young people who are the main audience in the social network prefer communication tools such as messaging applications. This is further evidence that interactive communication is an important tool in the development of new media.

\section{The role of the new media in shaping the public opinion}

Obviously, media has a strong influence on the development of civil society and shaping the public opinion. In the modern era, it acts as an educational media tool in order to understand the essence of socio-political and socio-economic events, to be aware of their rights and to be defended, to deal with various problems and to find their solution ways [6].

As the first model of the new media the portals, sites, and forums (Web 1.0 technologies) were developed in Azerbaijan. Consecutively, the Internet users now read topics, news, discuss them and express their opinions. Forums were the most widely spread platform for exchange of ideas. After a while, the information sites and social networking sites (Web 2.0 technologies) were created, which were a broader medium and provided a platform for users to share news, become content creators, and eventually become a direct information transmitter. Thus, a new source - a social media was added to the entertaining, informing and simultaneously educating traditional media.

Creating anonymous, fraudulent "profiles" is one of the factors that make the Internet users unable to display activity on the social networks. The young generation, experiencing problems in real life to expresses themselves, express their thoughts and attitude towards the events without 
hesitation in the virtual world. As a result, people begin to engage in discussions, exchange views, freely treat events, and acquire self-esteem skills in the society.

At the same time, the social networks have a great influence on shaping the ability to objectively communicate information, organize public events, facilitate meetings for charity purposes and form political discipline in the society.

Today, newspapers, radio, television and modern media become a mirror of the nation, and serve as a bridge between the government and society. For example, every government needs to convey the important decision in a manner that the citizens can understand. This mission must be fulfilled by the media [7].

According to the international rules, information transmitters, journalists, and speakers can not comment on the event and directly influence the viewer's opinion. They can only create opportunity for the viewer and reader to independently form attitude, by simply interpreting the issues.

\section{Distinguishing features of the new media from the traditional media}

The emergence of new media tools also creates a fundamental turning point in the activities of media representatives. The widespread use of social networks is observed by dramatic changes in the media industry. The term "individual media" has become an alternative to the concept of "mass media" at the expense of technological opportunities [7].

At the end of the 20th century, the media were classified by seven media types - books, newspapers, magazines, radio, movies, television and the Internet. From the beginning of the $21 \mathrm{st}$ century, the development of ICT has become one of the most prominent among them. The history of these media development is as follows:

Table 1

Development History of Media [6]

\begin{tabular}{|l|l|}
\hline Printing & From the end of the XV century; \\
\hline Audio-video recording (sound, video) & From the end of the 19th century; \\
\hline Movie & Since 1900; \\
\hline Radio & Since 1910; \\
\hline Television & Since 1950; \\
\hline Internet & Since 1990; \\
\hline Mobile phones & Since 2000 (massive use). \\
\hline
\end{tabular}

There are many differences between the traditional and new media:

- New media is faster than the traditional media;

- New media is open, the traditional media is closed;

- New media is addressed to users, traditional media - to the public;

- New media includes short texts, traditional media - long;

- New media provides the whole picture, traditional media - text;

- New media is active, traditional media is passive.

The important mission of the media is to inform the public about daily news and events. Media covers all aspects of our interests - weather forecast, political news, war, health, finance, science, fashion, music and more [8]. These innovations are measured only by the "clicks" through the media. Thus, users now use minutely updated mobile applications for different operating systems (mostly iOS and Android) to easily access information. "News", "Health", "Weather", "Music" and other relevant applications provide faster access to information.

The emergence of the Internet media has had a negative impact on the reputation of the traditional media types. Most factors such as offline media (television, radio, newspapers, etc.) and operability, objectivity, and consequently the credibility have been eliminated. The number of information sources was few; however, it is now countless. People get more complete, accurate and operative information from the sources they want and trust. In such a broader competitive 
environment, the traditional media should look for the ways to keep up with the audience and not lose the authority. Since, in any case, frequently changing audience and many representatives of the middle-aged generation are loyal to the traditional information sources.

Table 2

Comparison of online and offline data sources by different criteria [8]

\begin{tabular}{|c|c|c|}
\hline Criteria & Offline & Online (social media) \\
\hline strategy & to disseminate the news & to attract the audience \\
\hline time & limited & unlimited \\
\hline character & $\begin{array}{l}\text { more crushing, negative } \\
\text { information }\end{array}$ & interesting and positive news \\
\hline form & $\begin{array}{l}\text { program devoted to a specific } \\
\text { problem }\end{array}$ & free, non-interrelated topics \\
\hline propagation & specific media & user-based media \\
\hline communication & direct & indirect \\
\hline organizational & institution, organization & $\begin{array}{l}\text { ordinary people, professional } \\
\text { consumers, etc. }\end{array}$ \\
\hline $\begin{array}{l}\text { interaction with the } \\
\text { audience }\end{array}$ & limited interaction with the user & $\begin{array}{l}\text { user ability to comment on the } \\
\text { content; to contribute }\end{array}$ \\
\hline $\begin{array}{l}\text { duration of the content } \\
\text { (program) }\end{array}$ & longer & shorter \\
\hline
\end{tabular}

As the table shows, comparisons between offline and online media show that the latter has more opportunities.

Traditional television, radio and newspapers still exist, however it lacks behind online media in terms of interactivity, operability and pluralism. Experts state that compared to Web 1.0, the Web 2.0 model allows users not only to comment on the created content but also to create a new content within the topic and to upload photos [9]. This also serves the audience, listeners and readers for the disclosure of information and direct communication, and hence it serves the interests of the society and users.

Modern development of information technology has also created a new model of traditional television and radio - the Internet TV and the Internet radio. It is valued as an electronic medium with the information spread by hundreds and thousands of millions of people through the Internet TV and radio network, transforming the whole planet into the consumer of information. Aleksei Garmatin, an expert in this field, says: "Internet television is a network of open, constantly developing, multi-small and mid-video producers offering their programs [10]." Experts have come to a conclusion a few years ago that the Internet will overtake the traditional television in terms of audience accessibility [10]. Traditional radio and television have begun to create their own Internet versions, taking advantage of the new technology not to stay out of this fight. At present, many television and radio channels have internet access and can be watched over the Internet at any time. At the same time, there is an opportunity to access archived television, radio programs, news and content. The emergence of smart TVs allows traditional and Internet TVs to be integrated on the same platform and watched on the same screen.

Another advantage of contemporary media compared with traditional one is the emergence of the media economy. Thus, in the context of market economy, the commercial function is also added to the informative, awareness and enlightenment functions of media. In this context, economic values are also highlighted in the information production, along with other values (moral, ideological, etc.). In the Internet, the cost of data collection, editing and dissemination is minimized. Since the new media is capable to save the contents, they can be sold to the people on- 
line both through the traditional and e-trading technologies. This creates significant opportunities for the new media as a very important economic mechanism for paying and materializing the labor compensation for the authors, creative and technical group involved in the content generation [11].

Generally, paid marketing services in social media have created new opportunities for businessmen. Social media marketing is a set of measures to strengthen the company's image through social networking, advertising, campaigns, products promotion and service development. For example, today, Facebook is one of the world's largest advertising networks enabling the marketers to reach their goals. At the same time, Twitter, with its extensive audience statistics, now offers paid advertising services. New media tools predicted to overtake their traditional analogues in the near future due to the revenue gained from advertising [12].

Social media only offers paid advertising services. Effective preparation, planning and targeting of advertising are carried out by the companies dealing with Internet marketing. Social media marketing planning seems simple at first glance; however it is a time consuming process that requires professionalism.

The important factors for successful social media marketing include:

- regular communication with customers;

- $\quad$ quality content;

- holding campaigns and events;

- integration with various social media tools;

- $\quad$ software for mobile devices (iOS, Android, etc.)

- attracting new customers.

\section{New media and security problems}

The control over the Internet, media, and censorship are still unavailable. Although there are new media control mechanisms, discussions around new formulas are still continuing to completely prevent the threat. Children and teenagers are exposed to the negative impact of the Internet more and more. Here, most of the responsibility lies on parents. There are various software tools for information security, through which parents can restrict access to the sites and portals with criminal, non-ethical content that is the source of threat by downloading them on the computer.

Negative situations are also inevitable in such an environment offering unlimited opportunities to the public. The improvement of enforcement mechanisms to prevent disinformation in online media is also a significant problem. The spread of the information that cause risks of human life, through the Internet resources, privacy interference, explicit release of crimes, negative impacts on the psychology of children, pornographic images, movies and other negative materials are of great concern.

Sometimes users log in with fake names. As a result, provocative calls, negative thoughts, swearing and misinterpretations are spread by the person who is not actually in life. Identification of such individuals through IP address or other ways is a time-consuming process.

As a result of the information security threats, the country's political, economic, military and other spheres can be severely damaged, consequently, individual citizens and the society may face significant social and economic damage. The rapid increase in crime in the Internet is primarily due to the fact that this global network is open and accessible to all. It is not controlled by any state or organization [14]. The recently adopted legislation on the closure of the sites in Azerbaijan to ensure security in this field has begun to be executed. Thus, the Ministry of Transport, Communications and High Technologies appealed to the court to limit access to some specific resources. According to the latest amendment, the access to such sites may be also restricted without a court order. That is, the ministry can apply to the court even after closing the site. According to the current amendment, the court shall consider the application within 5 days [15]. 


\section{Conclusion}

With the emergence of the Internet, ICT has stepped into the new stage of journalism. In particular, the emergence of new media tools plays an indispensable role in organizing the work of journalists. Although some of the traditional media principles have been maintained, the new media is at a rapid stage of development, enabling journalists to independently share ideas, explore any news from the desktop, and, if necessary, edit just by pressing the "edit" button, or simply delete the news and to deliver it to millions and billions of people just in a few seconds. Mobile phones, which have become an integral part of our daily life, are the organizer, dictaphone, photovideo camera, and even mounting tool for journalists. Thus, as another type of media, mobile journalism is also one of the new media tools. This tool is an important factor in speeding up new media journalists.

New media tools also play an important role in establishing business relationships. In this sense, journalists need to positively use the interactivity of the Internet for their own purposes and appreciate these advantages properly and not misuse them. One of the great opportunities created by the online journalism for the traditional journalists is to share ideas that they can not easily express in newspapers, magazines, radio and television. At the same time, along with informing, educating and encouraging functions of media, its commercial functions have emerged the media economy through social media marketing, and revenue from advertising services.

As in all areas, the new media also has disadvantages. Since the audience in the Internet environment is not restricted, it should be taken into account that the shared information can be accessed by children and people with reduced psychology or poor heart. At this point the professional ethics and principles of honesty of the journalists should be one step ahead. In this sense, the new media should refer to the traditional media, not to explicitly present negative photos and videos, and not to broadcast unedited texts.

Thus, new media representatives are responsible for sharing accurate, objective, investigated, fact-based news stories in order to prevent the negative consequences. The traditional media still overtakes the new media by taking into account the age factor, the audience's psychology as a priority. The more careful online media journalists are, the more reliable source of information the new media will become. From this point of view, the new media should be transformed into a more credible information environment, and researchers should consider these problems in future scientific studies.

\section{References}

1. Austin A., Barnard J., Hutcheon N. New Media Forecast 2015. Zenith Optimedia, October 2015, 132 p.

2. https://www.en.wikipedia.org/wiki/New_media

3. https://www.statista.com/statistics/272014/global-social-networks-ranked-by-number-of-users

4. Feldman T. An Introduction to Digital Media. Taylor\&Francis e-Library. London and New York, 2005, 179 p.

5. http://www.journalistsresource.org/studies/society/news-media/top-10-digital-news-socialmedia-research

6. Sashwat Y. Role of media in social awareness // International Journal of Humanities and Social Sciences, Vol 1 (01) August 2013, pp.71-73.

7. Nalewajek M., Curie M. The role of social media in building awareness of responsible consumption Management, knowledge and learning. International conference, 2013, 839 p.

8. Alejandro J. Journalism in the age of social media. Reuters Institute Fellowship Paper. University of Oxford. Hilary and Trinity Terms, 2010, $47 \mathrm{p}$.

9. Briggs M. "Journalism 2.0: How to survive and thrive: A digital literacy guide for the information age", J-Lab: University of Maryland, 2007, 30 p. 
10. Mammadli J. The theory and practice of journalism. Textbook, 2012, $614 \mathrm{p}$.

11. Alguliyev R.M., Valehov J.F., Mahmudov R.Sh. Some aspects of Internet journalism formation. Express information. Information society series. Baku, "Information Technologies" publishing house, 2008, $32 \mathrm{p}$.

12. http://www.web.com.az/sosial-media-marketinq-ile-biznes-calismalar

13. http://www.saff.az/services/smm

14. Alguliyev R.M., Mahmudov R.Sh. Internet as a driving force of the development of society // Information society problems, Baku, "Information Technologies" publishing house, 2016, pp. $35-45$.

15. http://www.yeniavaz.com/NewsContent/ZNewsContent?id=43187\&total=41 